\title{
Desafios na formação de enfermeiros indígenas em Mato Grosso, Brasil
}

\author{
Challenges in the training of indigenous nurses in Mato Grosso, \\ Brazil
}

Vagner Ferreira do Nascimento (https://orcid.org/0000-0002-3355-163X) ${ }^{1}$

Thalise Yuri Hattori (https://orcid.org/0000-0003-4491-0375) ${ }^{1}$

Ana Cláudia Pereira Terças-Trettel (https://orcid.org/0000-0001-8761-3325) ${ }^{1}$
${ }^{1}$ Departamento de

Enfermagem, Universidade do Estado de Mato Grosso. MT-358 7, Jardim Aeroporto. 78300000 Tangará da Serra MT Brasil.

vagnerschon@hotmail.com

\begin{abstract}
The training of nurses in Brazil remain a challenge for the university, given the existing ethnic diversity and regional particularities. Thus, the aim of this study was to identify the challenges in the training process of indigenous nurses in Mato Grosso, Brazil. It is an exploratory and qualitative study, carried out with 11 indigenous nurses. Data analysis was based on Paulo Freire's interculturality. It was verified that both participants sought the integration of indigenous traditional knowledge with scientific technical knowledge during their practices, which facilitates a satisfactory interaction with the community. During nursing undergraduate school, they had little or no contact with contents related to indigenous health and at the end of the training they observed they were not prepared to meet the diverse health demands. Historically, they are subordinated in relation to non-indigenous people, which manifests as disadvantages in the teaching-learning process, related to technical / technological as well as social aspects.
\end{abstract}

Key words Education, Nursing, Nursing education programs, Professional competency, Cultural diffusion
Resumo A formação do enfermeiro no Brasil, ainda se apresenta como um desafio para as universidades, face as diversidades étnicas e as particularidades regionais existentes. Assim, o objetivo do estudo foi identificar os desafios no processo de formação de enfermeiros indígenas em Mato Grosso, Brasil. Trata-se de estudo exploratório e qualitativo, junto a 11 enfermeiros indigenas. A análise dos dados, baseou-se na interculturalidade de Paulo Freire. Verificou-se que todos participantes, buscam a integração dos saberes tradicionais indígenas com os conhecimentos técnico científicos, durante suas práticas, o que facilita a interação satisfatória com a comunidade. Durante a graduação de Enfermagem tiveram pouco ou nenhum contato com conteúdos relacionados à saúde indígena e ao término da formação vislumbravam despreparo para atender as variadas demandas em saúde. Historicamente, apresentam-se subalternizados em relação aos não indigenas, o que reflete em desvantagens no processo de ensino-aprendizagem, tanto relacionados aos aspectos técnicos/tecnológicos como sociais.

Palavras-chave Educação, Enfermagem, Competência profissional, Transculturação 


\section{Introdução}

A educação nas populações indígenas data do período colonial, tendo como proposta inicial a difusão de aspectos religiosos. No entanto, ao longo dos anos, essa educação foi sendo incorporada no cotidiano dessas comunidades, na perspectiva de aproximá-los do estilo de vida e dos bens de consumo dos não indígenas ${ }^{1}$. A expansão dessa educação reduziu os índices de analfabetismo da língua portuguesa, assim como estabeleceu uma cultura escolar nas comunidades indígenas, principalmente entre crianças e jovens ${ }^{2}$.

$\mathrm{Na}$ educação superior, o ingresso dos indígenas ocorreu em meados de 1990, por meio das celebrações de convênios entre a Fundação Nacional do Índio (FUNAI) e algumas instituições privadas e comunitárias ${ }^{3}$. A Lei Federal $n^{\circ}$ $12.711 / 2012$, viabilizou a oferta de vagas especiais ou suplementares em cursos regulares, o que ampliou as possibilidades de formação acadêmica de indígenas ${ }^{1}$.

A inserção de indígenas nos espaços acadêmicos trouxe alguns desafios, tendo em vista as dificuldades da Universidade em dialogar com esses povos, que apresentam tradição cultural, históricos e processos sociais distintos ${ }^{4}$. Essas particularidades exigem uma comunicação intercultural, a partir da compreensão da dinâmica dos saberes indígenas com os conhecimentos adquiridos na graduação ${ }^{5}$.

Embora, ainda que o ensino superior venha trabalhando na vertente da interculturalidade como forma de minimizar as barreiras invisíveis que marginalizam as minorias, nos cursos da área da saúde, permanece o predomínio de um modelo de currículo centrado na concepção biomédica, restrita ao processo saúde-doença, baseado na visão biolologicista, curativista e hospitalocêntrica, que contrapõe os saberes tradicionais ${ }^{6} . \mathrm{O}$ atual modelo curricular da maioria das Instituições de Ensino Superior (IES), provoca subordinação dos saberes indígenas, elimina a possibilidade dos conhecimentos tradicionais e extingue a possibilidade de produção de conhecimento desses povos ${ }^{4}$.

Diante disso, como forma de garantir os direitos à diversidade cultural e empoderamento dos saberes tradicionais nas práticas de cuidados, foi criado o Subsistema de Atenção à Saúde Indígena (SASI) idealizado na perspectiva de atenção diferenciada na parte organizacional e assistencial dos serviços de saúde e como parte integrante do Sistema Único de Saúde (SUS). A sua organização se faz por meio de 34 Distritos
Especiais Indígenas (DSEI) distribuídos por todo o território nacional. Trata-se de uma base territorial e populacional responsável pela operacionalização da referência e contra referência assistencial indígena. Nessa estrutura organizacional ainda existem os pólos base que atuam por meio das equipes de saúde diretamente dentro das comunidades indígenas 6 .

No âmbito acadêmico não é diferente, a ausência de projetos pedagógicos que consigam contemplar o mínimo dos elementos da interculturalidade indígena acarreta alguns obstáculos junto aos indígenas recém-formados, especialmente em relação ao enfrentamento da contradição em descontruir os saberes hegemônicos da medicina ocidental, e ao mesmo tempo a tarefa de aprender ou reaprender com os povos indígenas novas práticas da medicina tradicional. Esse processo constitui uma nova formação para o profissional indígena que extrapola a questão patológica, pois as questões cosmológicas e espirituais devem ser consideradas e poderão influenciar nas práticas de cuidados ${ }^{7}$.

Em Mato Grosso, essas circunstâncias se mostram ainda mais desafiadoras uma vez que o estado possui a maior diversidade étnica de indígenas do país, com hábitos e costumes diversos. Dessa forma, atentos a essas características e ao desejo na formação intercultural, em 2001 a Universidade do Estado de Mato Grosso (Unemat) criou a faculdade intercultural indígena, pioneira no Brasil e na américa latina. Todavia, essa formação se concentrou nas licenciaturas, sobremaneira na formação de docentes. Nesse período, outras IES do Estado também buscaram estabelecer ações afirmativas e meios para integrar os indígenas à Universidade ${ }^{3}$.

Como resultado desse movimento, muitos indígenas ingressaram em IES do Estado, particularmente em cursos na área da saúde. Entre esses cursos, a Enfermagem se destaca, já que muitos indígenas desejam contribuir com a comunidade, ao suprir no dia-a-dia as necessidades básicas de saúde do seu povo e garantir a preservação das tradições. Apesar disso, o aumento no ingresso de indígenas nas universidades não representou crescimento de enfermeiros indígenas no Estado, pois o percentual de desistência durante o curso ainda é alto ${ }^{3,8}$. Talvez, um dos motivos para esse panorama seja a criação de forma desorganizada de cursos de Enfermagem no país e que não atendam às características regionais ${ }^{9}$.

Portanto, um bom planejamento articulado com as políticas e estratégias de ensino que estejam direcionadas para uma educação inter- 
cultural e transformadora, na compreensão das demandas e cenários socioculturais dos futuros enfermeiros indígenas, podem subsidiar possíveis reflexões, mudanças e/ou melhorias. Diante disso, o estudo teve como objetivo identificar os desafios no processo de formação de enfermeiros indígenas em Mato Grosso, Brasil.

\section{Métodos}

Trata-se de estudo exploratório, com abordagem qualitativa, seguindo a Consolidated Criteria for Reporting Qualitative Research (COREQ). O estudo foi conduzido em Mato Grosso, terceiro maior Estado em extensão territorial do Brasil, com limite entre os Estados do Amazonas, Pará, Rondônia, Tocantins, Goiás e Mato Grosso do Sul, e com fronteira internacional (Bolívia). Possui 48 etnias indígenas, distribuídas em meio a três biomas, Floresta Amazônica, Pantanal e Cerrado. Mato Grosso conta com duas universidades públicas, com o curso de Enfermagem em sete campus universitários. Ambas universidades, possuem cotas para indígenas, sendo a estadual com reserva fixa de $5 \%$ em cada curso e a federal com percentual variado, conforme disponibilidade de vagas. As principais etnias presentes nessas universidades são: Arara, Bakairi, Bororo, Chiquitano, Guató, Irantxe, Karajá, Nhambiquara, Paresi, Terena, Umutina, Xavante e Yawalapiti.

Foram incluídos no estudo, enfermeiros autodeclarados indígenas com formação em Enfermagem nas universidades públicas de Mato Grosso e com atuação profissional mínima de 12 meses na saúde indígena (aldeia e/ou casa de saúde indígena). Foram excluídos enfermeiros que não compreendessem o idioma Português (Brasil). A amostragem do estudo foi do tipo não probabilística, através estratégia snowball sampling, sendo que o tamanho amostral ocorreu pelo método de saturação de dados, até alcançar o objetivo do estudo. Assim, ingressaram no estudo 11 enfermeiros indígenas, sem desistências.

Inicialmente, houve o contato com um enfermeiro indígena conhecido pela equipe de pesquisadores, que possibilitou o conhecimento e encontro com os demais participantes do estudo. Os dados foram coletados entre os meses de outubro e dezembro de 2017, por meio de entrevista individual, seguindo uma questão norteadora "Como foi sua formação em Enfermagem, levando em consideração os saberes da cultura indígena e os conhecimentos científicos adquiridos?”. Os participantes tiveram a oportu- nidade de explanar livremente, sem interferência do pesquisador, suas vivências frente ao percurso acadêmico e a efetivação como enfermeiro junto à comunidade indígena. Utilizou-se gravador de multimídia para ampliar o poder de registro e captação dos elementos de comunicação, dado as variações de linguagem.

As entrevistas tiveram duração média de 25 minutos, sendo realizadas no ambiente de escolha dos participantes. Para preservação do anonimato, utilizou-se a codificação alfanumérica, de modo que a letra "E" indica enfermeiro e o elemento numérico que acompanha o conjunto apenas indica a ordem da narrativa no desenvolvimento da análise.

Assim, após a conclusão das entrevistas, o material empírico foi transcrito e analisado pela técnica de análise de conteúdo, na modalidade temática, seguindo três etapas: pré-análise, exploração do material, tratamento dos resultados: inferência e interpretação ${ }^{10}$. A análise foi fundamentada na interculturalidade do pensamento educacional de Paulo Freire. A interculturalidade não compreende apenas a existência de diversidades culturais e suas particularidades, mas volta-se especialmente a valorização, respeito e encorajamento às relações interculturais no espaço de ensino-aprendizagem, de modo a viabilizar o potencial humano e o fomento dos saberes populares e científicos ${ }^{11}$.

Dessa análise, originaram-se três categorias: 1) Integração dos saberes populares indígenas com o conhecimento adquirido na formação; 2) Conhecimentos necessários para atuar com indígenas; e 3) Dificuldades enfrentadas durante a formação como enfermeiro.

Este estudo respeitou todos aspectos éticos em pesquisa, sob aprovação do Conselho Nacional de Ética em Pesquisa (CONEP) e Certificado de Apresentação para Apreciação Ética (CAAE). Todos os participantes do estudo assinaram o Termo de Consentimento Livre e Esclarecido (TCLE).

\section{Resultados}

Os indígenas participantes do estudo possuíam de 22 a 52 anos, predominando o sexo masculino, casados com filhos e com média de oito anos de atuação como enfermeiros. A primeira oportunidade de emprego foi em área indígena (aldeia) ou em Casa de Saúde Indígena (CASAI) em municípios polo. Em relação a formação complementar, prevaleceu pós-graduação lato sensu em saúde indígena e saúde da família. 
$\mathrm{Na}$ Categoria 1, para alguns participantes, o êxito das práticas de cuidados ocorre na medida que não viole os conhecimentos tradicionais. Para isso, apontam primeiramente o respeito a cultura como melhor caminho, de modo que haja o equilíbrio entre ambas medicinas (tradicional e ocidental). No entanto, alguns evidenciam que a ausência desses saberes sobre a saúde indígena durante a formação só não teve tantos prejuízos, pois eram indígenas e conheciam a cultura de cuidado do seu povo.

$\mathrm{Na}$ Categoria 2, os enfermeiros externam a necessidade de inclusão de conteúdos sobre saúde indígena durante a formação, contemplando a maior quantidade de etnias e aspectos que determinam o processo saúde-doença. Revelam que há pouca preocupação/motivação do curso/ faculdade em atender as demandas do estado e considerar a diversidade étnica existente. Ressaltam ainda a importância da vivência direta com a saúde indígena e com o cotidiano assistencial dessas comunidades durante as atividades de estágio, como essenciais para a formação do enfermeiro.

$\mathrm{Na}$ Categoria 3, as dificuldades enfrentadas durante a formação como enfermeiro advém, especialmente, da educação básica, trabalhada somente na ciência do fortalecimento da identidade cultural indígena nas aldeias e pelo contato tardio com as tecnologias (computador e acesso à internet). Sofrem preconceito e/ou exclusão frente ao estereótipo culturalmente marginalizado pelos não indígenas e ainda se esbarram em demandas financeiras que oneram seus custos de vida, impondo desafios à permanência na Universidade (Quadro 1).

\section{Discussão}

Para os indígenas, o significado de saúde ou mesmo os horizontes para a formação e concretização dos saberes em saúde, fundamentos que percorrem o processo de aprendizagem durante toda a graduação de Enfermagem estão relacionados ao conjunto de conhecimentos tradicionais trazidos de suas dimensões étnicas. Esses saberes constituem uma forma de representação social do modo de compreender o processo saúde-doença ${ }^{12}$. Mas, para isso, os saberes tradicionais indígenas e os conhecimentos técnico-científicos devem se comunicar harmoniosamente, quer seja na literatura, quer seja nos discursos e práticas pedagógicas durante a graduação, a fim de fortalecer o aprendizado do acadêmico/futuro enfermeiro, na perspectiva de instrumentalizar múltiplos recursos terapêuticos.

Pesquisas com indígenas reforçam a importância da articulação da intermedicalidade nas práticas terapêuticas, uma vez que esses povos possuem percepções peculiares quanto saúde, doença e adoecimento ${ }^{6,12}$. Para essa integração na vivência dos participantes do estudo, o melhor caminho é o respeito à cultura, que segundo Paulo Freire ${ }^{13}$, ao considerar o outro em suas particularidades e tradições, há partilha de saberes e instituição de mecanismos de garantia de reconhecimento, valorização e igualdade.

No Brasil, as legislações nacionais aplicadas à formação, como a Lei de Diretrizes e Bases da Educação Brasileira (LDB) e as Diretrizes Curriculares Nacional (DCN) possuem entre suas finalidades, a promoção e divulgação do conhecimento científico cultural, tanto regional como nacional. Na Enfermagem, especificamente, esse aparato legal direciona para a elaboração de propostas curriculares alinhadas ao pluralismo e contexto do território ${ }^{14}$.

No entanto, a formação do enfermeiro em vários projetos pedagógicos do país exclui a integração das variadas culturas existentes, e nesse interim, desconsideram as heterogeneidades étnicas dos brasileiros ${ }^{14}$. Limitam-se a imposição e não a inclusão ${ }^{15}$. Cabe ressaltar que a inclusão das singularidades indígenas no currículo é complexa e ampla, devendo iniciar a partir do conhecimento das etnias existentes no entorno de cada IES $^{16}$.

Não obstante, ao manterem o direcionamento didático-pedagógico engessado e verticalizado, a formação do enfermeiro, assim como descrito nas narrativas, amputa alguns cenários assistenciais que podem constituir oportunidades de ingresso profissional, como por exemplo, a saúde indígena. Se por um lado, os participantes do estudo apontam que ser indígena foi fator decisivo e auxiliou para que os conflitos de concepções do processo saúde-doença fossem minimizados durante a assistência à população indígena, por outro, o conhecimento que estes enfermeiros possuem em relação à sua cultura e etnia não se aplica diretamente a outras, e talvez não se sustente em contextos não indígenas, pela falta de articulação dos conhecimentos apresentados durante a formação.

Nesse sentido, a pedagogia potencial a ser aplicada na formação e consolidação dos saberes do enfermeiro deve responder aos desafios da interculturalidade e promoção das humanidades, que possuem reflexos diretos em diversas am- 
Quadro 1. Distribuição e categorização das narrativas dos participantes.

\begin{tabular}{|c|c|c|c|}
\hline Categorias & \multicolumn{3}{|c|}{ Narrativas } \\
\hline $\begin{array}{l}\text { Categoria } \\
1 \text { - Integração } \\
\text { dos saberes } \\
\text { indígenas } \\
\text { com os } \\
\text { conhecimentos } \\
\text { adquiridos na } \\
\text { formação. }\end{array}$ & $\begin{array}{l}\text { Nós, profissionais indígenas, } \\
\text { temos que buscar um equilíbrio } \\
\text { no cuidado, visto que a medicina } \\
\text { ocidental é científica; já a indígena } \\
\text { é a união da espiritualidade, ervas } \\
\text { e benzimento. (E3) } \\
\text { Acho que é não impor meu } \\
\text { novo conhecimento científico } \\
\text { diante do deles. Esperar sempre o } \\
\text { primeiro passo, os costumes serem } \\
\text { apresentados e ir modelando. (E7) } \\
\text { Sempre procurei respeitar a minha } \\
\text { cultura com a dos não indígenas, e } \\
\text { isso vem dando certo nas minhas } \\
\text { práticas, no trabalho. (E9) }\end{array}$ & $\begin{array}{l}\text { Sempre haverá conflitos } \\
\text { culturais. Na faculdade não foi } \\
\text { muito trabalhada a questão } \\
\text { indígena e, se eu não fosse } \\
\text { indígena, teria saído mais } \\
\text { perdida do que entrei em relação } \\
\text { à saúde dos nossos povos. (E1) } \\
\text { [...] durante o curso de } \\
\text { Enfermagem não era aberto para } \\
\text { discutir temática indígena em } \\
\text { sala de aula. (E6) } \\
\text { Nossa cultura indígena } \\
\text { tem especificidades, então } \\
\text { é importante conhecer com } \\
\text { antecedência esses aspectos, } \\
\text { para que não entre em conflito e } \\
\text { consiga estreitar vínculo com a } \\
\text { comunidade. (E8) }\end{array}$ & $\begin{array}{l}\text { Quem é indigena, } \\
\text { não é difícil articular } \\
\text { os conhecimentos, } \\
\text { depois que forma. } \\
\text { Trabalhamos em } \\
\text { conjunto com parteiras } \\
\text { e pajés, associando } \\
\text { os saberes. Sempre } \\
\text { estamos auxiliando, é } \\
\text { uma forma de cuidado } \\
\text { cooperativo. (E10) } \\
\text { Para o enfermeiro não } \\
\text { indio é mais difícil, leva } \\
\text { tempo para entender e } \\
\text { aprender. Para evitar } \\
\text { o conflito você deve } \\
\text { valorizar os saberes } \\
\text { tradicionais e tentar } \\
\text { sensibiliza-los. (E11) }\end{array}$ \\
\hline $\begin{array}{l}\text { Categoria } 2 \text { - } \\
\text { Conhecimentos } \\
\text { necessários } \\
\text { para atuar com } \\
\text { indígenas. }\end{array}$ & $\begin{array}{l}\text { Visões diferentes de saúde } \\
\text { que não a europeia, do norte, } \\
\text { ocidentalizada. Talvez, sobre } \\
\text { história do Brasil com ênfase na } \\
\text { visão indígena da colonização, do } \\
\text { genocídio indígena e impacto na } \\
\text { concepção de saúde-doença. (E1) } \\
\text { O sistema de vida! Só que cada } \\
\text { povo tem um sistema diferente, os } \\
\text { professores poderiam pelo menos } \\
\text { realizar um consolidado de alguns } \\
\text { povos, em razão da diversidade } \\
\text { étnica e especificidades. (E2) } \\
\text { Poderia falar das etnias, afinal } \\
\text { cada uma tem sua especificidade } \\
\text { diante do território em que vive. } \\
\text { Entrar um pouco na política } \\
\text { de saúde indígena do Brasil, } \\
\text { principalmente na visão do } \\
\text { processo saúde-doença. (E5) }\end{array}$ & $\begin{array}{l}\text { [...] nenhum enfermeiro da } \\
\text { minha turma saiu preparado ou } \\
\text { com alguma noção sobre saúde } \\
\text { indigena [...]. (E7) } \\
\text { Seria importante incluir no } \\
\text { curso de Enfermagem o conteúdo } \\
\text { de saúde indígena visto que o } \\
\text { acadêmico se forma e muitas } \\
\text { vezes seu primeiro emprego é na } \\
\text { saúde indígena. (E8) } \\
\text { A Universidade deve levar } \\
\text { os alunos para as aldeias, } \\
\text { para conhecer realmente o } \\
\text { que é saúde indígena. Muitos } \\
\text { conflitos ocorrem por falta de } \\
\text { conhecimento sobre a cultura e } \\
\text { as tradições. (E10) }\end{array}$ & $\begin{array}{l}\text { [...] acho que trazer os } \\
\text { alunos para os espaços } \\
\text { e contexto culturais } \\
\text { indígenas e suas visões } \\
\text { de saúde ajudariam na } \\
\text { formação. (E6) } \\
\text { Deveria ter tido estágio } \\
\text { dentro das unidades } \\
\text { básicas de saúde } \\
\text { indígena, porque caso } \\
\text { algum acadêmico } \\
\text { queira, depois de } \\
\text { formado atuar na área, } \\
\text { não ficará perdido, não } \\
\text { perderá tempo, pois terá } \\
\text { uma formação mais } \\
\text { completa [...]. (E11) }\end{array}$ \\
\hline $\begin{array}{l}\text { Categoria } 3 \text { - } \\
\text { Dificuldades } \\
\text { enfrentadas } \\
\text { durante a } \\
\text { formação como } \\
\text { enfermeiro. }\end{array}$ & $\begin{array}{l}\text { O ensino fundamental e médio é } \\
\text { precário, por isso tive que estudar } \\
\text { mais que os colegas para suprir as } \\
\text { deficiências que tive em relação } \\
\text { ao português e a interpretação de } \\
\text { estudos de casos. (E2) } \\
\text { A maior dificuldade foi não ter } \\
\text { habilidade com internet, pois na } \\
\text { aldeia não tínhamos acesso na } \\
\text { época. (E8) } \\
\text { [...] o ensino nas aldeias não é tão } \\
\text { evoluído como na cidade, aí fica } \\
\text { difícil, principalmente por que } \\
\text { nossa língua materna é diferente. } \\
\text { (E9) }\end{array}$ & $\begin{array}{l}\text { As dificuldades que nós } \\
\text { indígenas tivemos éo } \\
\text { preconceito. Então nos } \\
\text { apoiávamos em outros colegas } \\
\text { que também eram universitários. } \\
\text { (E5) } \\
\text { A dificuldade foi nos olhares de } \\
\text { alguns professores e também } \\
\text { alunos. Assim busquei superar } \\
\text { isso estudando mais, para que o } \\
\text { preconceito fosse mais leve. (E6) } \\
\text { O pior é sentir-se excluído } \\
\text { dos demais da turma, porque } \\
\text { você é o diferente, idioma, } \\
\text { características físicas, velocidade } \\
\text { na aprendizagem. (E7) }\end{array}$ & $\begin{array}{l}{[. . .] \text { dificuldade }} \\
\text { financeira, as bolsas } \\
\text { ajudaram bastante, } \\
\text { foi minha salvação } \\
\text { para permanecer na } \\
\text { Universidade. (E3) } \\
\text { Tinha dificuldades com } \\
\text { dinheiro para custear } \\
\text { apostilas, procurava } \\
\text { saber do conteúdo e } \\
\text { usava o laboratório } \\
\text { de computação para } \\
\text { ler sobre conteúdo } \\
\text { pendente sem apostila. } \\
\text { (E11) }\end{array}$ \\
\hline
\end{tabular}


biências de ensino e cuidado, de acordo com as demandas de reminiscências e patrimônios que envolvem esses grupos ${ }^{17}$. Assim, tanto os enfermeiros indígenas como não indígenas, conforme Paulo Freire ${ }^{13}$, podem ser beneficiados com uma formação transcultural, e impactar positivamente na assistência, uma vez que conseguirão integrar os diversos saberes e, além disso, agregarem os profissionais às equipes de cuidado legitimado e de referência da comunidade indígena (pajés, curandeiros e parteiras), em prol da integralidade de uma prática transcultural, em que se deixa de considerar tais conhecimentos em dualidade, e sim como essenciais e complementares.

Essa integralidade, apontada pelos participantes do estudo, direciona-se para o entendimento da pluralidade dos povos indígenas existentes no país, exigindo o mínimo de reconhecimento quanto a sua diferença em relação ao aspecto histórico, político, social, cultural, econômico, ecológico, linguístico e de sua própria organização, para, então, compreender as particularidades do cuidar no contexto indíge$\mathrm{na}^{12}$. Essa imersão das práticas pedagógicas baseada nas bases epistêmicas interculturais, tende a favorecer a interação com os povos indígenas e integrar os saberes e valores ${ }^{13}$.

No campo de atuação dos profissionais da saúde indígena, o maior desafio é quanto ao despreparo para atuarem em contextos interétnicos heterogêneos. As iniciativas de capacitação dos profissionais da saúde indígena em que pouca ou nenhuma ênfase é dada aos aspectos etnológicos e antropológicos, agravam ainda mais essa situação ${ }^{18}$. Tal despreparo, conforme observado nas narrativas, repercute na ausência de ações, como a inclusão da disciplina saúde indígena nas grades curriculares de formação técnica e superior.

Contudo, observa-se que a graduação ainda está longe de contribuir para a atuação de profissionais da saúde sensíveis nos contextos interétnicos, interculturais e às realidades plurais a que pertencem ${ }^{19}$, como desconsidera-se as práticas e saberes tradicionais indígenas, prática esta que contraria ao que é estabelecido pela Política Nacional de Atenção à Saúde dos Povos Indígenas (PNASPI) e pela SASI. Essa prática hegemônica da medicina ocidental na saúde indígena também foi observada em outras pesquisas realizadas em Brasília ${ }^{6}$, Mato Grosso ${ }^{12}$, Paraíba $^{20}$, Tocantins ${ }^{21}$ e Pará2 ${ }^{2}$.

A compreensão dos aspectos antropológicos, pedagógicos e linguísticos no ensino ou na extensão, são fundamentais para compreender as dimensões interétnicas, assim como apresentado pelos participantes. Nessa perspectiva, o acadêmico se torna ator do seu processo de aprendizagem como sujeito participativo, crítico e reflexivo, mediante a dialogicidade entre educador, educando e entre as realidades humanas ${ }^{23,24}$.

Pensando nesse contexto, os Ministérios da Saúde e Educação instituiram em 2008, o Programa de Educação pelo Trabalho para a Saúde (PET- Saúde) que fomenta a integração ensinoserviço-comunidade nos processos de formação profissional da área da saúde. Essa nova estratégia amplia as mudanças do modelo de formação e reorienta as práticas de atenção à saúde do SUS. A Universidade de Brasília (UnB), por meio do PET-Saúde Indígena, já traz uma experiência exitosa da construção e fortalecimento das redes interculturais em saúde, idealizada por estudantes indígenas da instituição $0^{6}$.

Tais sucessos, evidenciam que a interlocução da teoria com a prática, por meio das bases epistemológicas e metodológicas interculturais, devem ser oportunizadas durante à graduação de Enfermagem, em especial em regiões como o Estado de Mato Grosso, em que o perfil populacional contempla particularidades distintas, exigindo a aproximação com o cotidiano desses povos e resgate de aspectos históricos e antropológicos que fundamentarão as práticas dialógicas entre os saberes científicos, humanísticos, populares e tradicionais, e, consequentemente, alcançar os modos de aprender, ser e fazer o cuidado ${ }^{12}$. Esse direcionamento estratégico, favorecerá uma formação mais integral, com entendimento do processo de trabalho do enfermeiro junto à comunidade e frente às diversidades assistenciais.

Uma das formas de reduzir essas diferenças culturais consiste na implementação de propostas curriculares diferenciadas voltadas para o atendimento das características indígenas, assim como já adotado no ensino básico. Entretanto, no ensino superior, principalmente nos cursos de bacharelado, como na Enfermagem, pouco tem se preocupado em atender a amplitude epistêmica e metodológica a qual está inserida ${ }^{25}$.

Estudos nacionais abordando a saúde indígena identificam a interculturalidade como um dos principais desafios enfrentados na prática assistencial, permeado pela dificuldade de comunicação e pelo desconhecimento por parte dos profissionais (a maioria não indígena) quanto aos aspectos culturais. Esses aspectos podem ser reflexo da fragilidade curricular da graduação que se perpetua mesmo após a formação ${ }^{16,18}$.

Dificuldades com o idioma, acompanhamento de conteúdo específicos e enfoque curricular 
(ensino básico) diferenciado foram ressaltados pelos participantes como elementos desse confronto e complexidade na formação. Sendo assim, a sensibilização institucional em realizar interação dialógica é o primeiro passo para a efetivação da interculturalidade nas universidades e para a construção de relações entre grupos socioculturais variados ${ }^{4}$.

Outro paradoxo observado nas narrativas é que, apesar das IES viabilizarem as ações afirmativas para os indígenas, a maioria destas não apresenta uma política planejada de acesso e permanência que consiga conduzir para um bom desempenho do acadêmico e proporcione uma formação com qualidade. Esses fatores, principalmente nas fases iniciais, acarretam índices maiores de evasão ${ }^{1}$. Nesse prisma, não basta apenas fornecer o auxílio financeiro por meio de bolsas, e sim pensar em estratégias longitudinais que incluam também os aspectos pedagógicos que envolvam tanto a questão de infraestrutura, como de acompanhamento das fragilidades durante todo o processo de formação do enfermeiro.

Vários participantes pontuaram também como rotina durante a formação o preconceito e julgamento por parte dos não indígenas. Porém, procuram utilizar os princípios estabelecidos nas aldeias como a austeridade, força e coletividade para continuarem persistentes na academia. $\mathrm{Ob}$ serva-se ainda que, por mais que a Universidade teoricamente trabalhe na concepção da diversidade, aberta a todos os grupos sociais, as práticas acadêmicas são majoritariamente padronizadas ${ }^{17}$.

De acordo com Paulo Freire ${ }^{23}$, as lacunas existentes entre indígenas e não indígenas no ambiente acadêmico, podem ser superadas com a prática diária proposta pela educação transcultural que evidencia as necessidades dos indivíduos em atravessarem suas próprias fronteiras culturais em direção ao outro, na forma de interação, contato, aceitação e troca, que seja transformadora, significativa e respeitosa entre aqueles que partilham suas diferenças culturais no sistema educativo.

Ademais, tão ou mais importante do que realizar a sensibilização dos estudantes e demais segmentos da instituição, é inserir o docente nos debates interculturais, uma vez que envolverá a transformação de suas práticas pedagógicas, agregando valor à docência, de forma que seja inclusiva, ética e emancipatória. Os processos formativos devem estar focados nessa problemática, já que a educação intercultural vislumbra a formação para a cidadania bem como a superação de preconceitos e discriminação ${ }^{26}$.
Todas as dificuldades relatadas pelos participantes do estudo foram similares a estudos nacionais que avaliaram as políticas de acesso e permanência dos estudantes indígenas das universidades brasileiras ${ }^{1,21,22}$. Observa-se, portanto que, independente da graduação, os desafios enfrentados pelos acadêmicos indígenas são comuns, assemelhando-se, principalmente pelas questões econômicas, culturais e históricas.

\section{Considerações finais}

Os participantes do presente estudo, revelam que em seu cotidiano assistencial há integração dos saberes tradicionais indígenas com os conhecimentos técnico-científicos. E, por serem indígenas, o processo de articulação desses saberes se mostra menos complexo em detrimento de outros enfermeiros, não indígenas. $\mathrm{O}$ trabalho de Enfermagem que desenvolvem junto à essa população, baseia-se no respeito à cultura e tradições, o que fortalece os vínculos e os cuidados em saúde, entre profissionais e lideranças da comunidade indígena.

Apesar de apontarem harmonia nas práticas de cuidados junto às comunidades, reconhecem que não tiveram nenhuma disciplina durante a graduação de Enfermagem que apresentasse o contexto indígena e suas particularidades no processo saúde-doença, bem como que permitisse a vivência direta junto a estes povos. Observa-se, portanto, que mesmo com o aparato legal das DCN, no curso de Enfermagem ainda existe uma lacuna a ser superada quanto a elaboração de currículos que considerem o contexto territorial e o pluralismo cultural, como é o caso do Estado de Mato Grosso.

Outra problemática observada, é a afirmação que professores e a própria Universidade pouco se preocupam ou desconhecem as demandas regionais e diversidades étnicas, assim como suas implicações e a importância da interculturalidade no processo de formação do enfermeiro. E ao banalizarem a existência dessas diversidades durante a formação acadêmica, não oportunizam saberes necessários para a formação transcultural do enfermeiro e ampliam a distância entre indígenas e não indígenas frente às práticas de cuidado em saúde e Enfermagem.

Todavia, o indígena apresenta algumas fragilidades históricas, em reflexo do confronto de currículos oportunizados ao longo de sua vida, daquele pensado no atendimento das necessidades enquanto criança indígena no ensino funda- 
mental com o currículo estabelecido no contexto do ensino médio e universitário. Esse desencontro, contribui para a existência de constantes dificuldades tanto em caráter técnico/tecnológico como social, que acabam impondo barreiras para a continuidade da graduação.

Diante desses desafios, há necessidade de ampliação dos diálogos em relação as políticas de ensino voltadas aos indígenas, fundamentalmen- te quanto a formação do enfermeiro indígena. Para isso, a adesão às diretrizes e práticas pedagógicas transculturais que valorizem a interculturalidade durante a graduação de Enfermagem deve ser priorizada, de modo que, além de garantir o acesso à Universidade e bolsas, proporcione uma formação de qualidade para os diversos cenários em saúde.

\section{Colaboradores}

VF Nascimento: Concepção e delineamento do projeto, coleta e análise de dados, confecção dos resultados e discussão, redação e revisão crítica, aprovação da versão final. TY Hattori: Coleta e análise de dados, discussão dos dados, redação e revisão crítica, aprovação da versão final. ACP Terças-Trettel: Coleta e análise de dados, discussão dos dados e redação. 


\section{Referências}

1. Bergamaschi MA, Doebber MB, Brito PO. Estudantes indígenas em universidades brasileiras: um estudo das políticas de acesso e permanência. Rev bras estud pedagog [periódico na Internet]. 2018 Jun. [acessado 2019 Mar 05]; 99(251):37-53. Disponível em: https:// doi.org/10.24109/2176-6681.rbep.99i251.3337

2. Melo ALA, Moura Filho JL. Populações tradicionais e inclusão social no Brasil: Um paralelo entre as políticas de acesso à terra e à educação superior por indígenas e quilombolas. Cahiers ALHIM [periódico na Internet]. 2018 Jan. [acessado 2019 Mar 05]; 36. Disponível: http://journals.openedition.org/alhim/7019

3. Lima ACS. Ações afirmativas no ensino superior e povos indígenas no Brasil: uma trajetória de trabalho. Horiz Antropol [periódico na Internet]. 2018 Jan. [acessado 2019 Mar 05]; 24(50):377-448. Disponível em: http://dx.doi.org/10.1590/s0104-7183201800010 0013

4. Urquiza AHA. Direitos humanos e educação intercultural: as fronteiras da exclusão e as minorias sub -representadas - os indígenas no ensino superior. Ser-estud [periódico na Internet]. 2014 Jun. [acessado 2019 Mar 05]; 37:141-154. Disponível em: http:// www.serie-estudos.ucdb.br/index.php/serie-estudos/ article/view/774

5. Silva AA, Ferreira WAA, Ferreira LL. As etapas intermediárias como espaço de formação na licenciatura intercultural: interações e nexos entre Aldeia - Universidade. Rev educ pública [periódico na Internet]. 2017 Jan. [acessado 2019 Mar 05]; 26 (62):421-432. Disponível em: http://periodicoscientificos.ufmt.br/ ojs/index.php/educacaopublica/article/view/5003

6. Hoefel MGL, Severo DO, Bermudez XP, Hamann EM, Carvalho HS. PET- Saúde Indígena UnB: construindo redes interculturais em saúde. Tempus (Brasília) [periódico na Internet]. 2015 Jun. [acessado 2019 Mar 05]; 9(1):43-63. Disponível em: http://www.tempusactas. unb.br/index.php/tempus/article/view/1691/1398

7. Fleuri RM. Aprender com os povos indígenas. Rev educ pública [periódico na Internet]. 2017 Jan. [acessado 2019 Mar 05]; 26(62):277-294. Disponível em: http://periodicoscientificos.ufmt.br/ojs/index.php/ educacaopublica/article/view/4995

8. Machado MH, Wermelinger M, Vieira M, Oliveira E, Lemos W, Aguiar Filho W, Lacerda WF, Santos MR, Souza Júnior PB, Justino E, Barbosa C. Aspectos gerais da formação da enfermagem: o perfil da formação dos enfermeiros, técnicos e auxiliares. Enferm Foco [periódico na Internet]. 2016 Fev. [acessado 2019 Mar 05]; 6(4):15-34. Disponível em: https://doi.org/10.21675/ 2357-707X.2016.v7.nESP.687

9. Thumé E, Fehn AC, Acioli S, Fassa MEG. Formação e prática de enfermeiros para a Atenção Primária à Saúde - avanços, desafios e estratégias para fortalecimento do Sistema Único de Saúde. Saúde Debate [periódico na Internet]. 2018 Set. [acessado 2019 Mar 05]; 42 (sppl.1):275-288. Disponível em: http://dx.doi. org/10.1590/0103-11042018s118

10. Bardin L. Análise de conteúdo. São Paulo: Edições 70; 2011.
11. Oliveira IA. Cultura e interculturalidade na educação popular de Paulo Freire. EccoS rev cient [periódico na Internet]. 2011 Jun. [acessado 2019 Mar 05]; 25:109124. Disponível em: https://doi.org/10.5585/eccos. $\mathrm{n} 25.3219$

12. Baggio E, Nascimento VF, Terças ACP, Hattori TY, Atanaka M, Lemos ERS. O cuidar da saúde para a mulher indígena Haliti-Paresí. Rev enferm UFPE on line [periódico na Internet]. 2018 Mar. [acessado 2019 Mar 05]; 12(3):729-737. Disponível em: https://doi. org/10.5205/1981-8963-v12i3a22870p729-737-2018

13. Freire P. Pedagogia do oprimido. Rio de Janeiro: Paz e Terra; 2001.

14. Franco ECD, Soares NA, Bethony MFG. Currículo integrado no ensino superior em enfermagem: o que dizem os enfermeiros docentes. Enferm Foco [periódico na Internet]. 2016 Jun. [acessado 2019 Mar 05]; 7(1):33-36. Disponível em: https://doi.org/10.21675/ 2357-707X.2016.v7.n1.662

15. Fontana RT. A interculturalidade na formação dos profissionais de enfermagem. Rev contexto educ [periódico na Internet]. 2019 Ago. [acessado 2019 ago 30]; 34(109):36-51. Disponível em: https://doi. org/10.21527/2179-1309.2019.109.36-51

16. Castro NJC. O ensino da saúde indígena nos currículos e espaços acadêmicos. Rev ensino saúde ambien [periódico na Internet]. 2015 Jan. [acessado 2019 Mar 05]; 8(1):15-25. Disponível em: https://doi. org/10.22409/resa2015.v8i1.a21197

17. Severo JLRL. Dimensões socializadoras do currículo na perspectiva de uma Pedagogia Social: algumas aproximações. Rev educ ciênc cult [periódico na Internet]. 2018 Mar. [acessado 2019 Mar 05]; 23(3):157167. Disponível em: https://doi.org/10.18316/recc. v23i3.4121

18. Diehl EE, Pellegrini MA. Saúde e povos indígenas no Brasil: o desafio da formação e educação permanente de trabalhadores para atuação em contextos interculturais. Cad Saúde Pública [periódico na Internet]. 2014 Abr. [acessado 2019 Mar 05]; 30 (4):867-874. Disponível em: http://dx.doi.org/10.1590/0102-311X 00030014

19. Silva DOM, Santos DA, Nery FKP, Costa Filho AA, Santana LAA. A interculturalidade na formação: a experiência do bacharelado interdisciplinar em saúde da Universidade Federal do Recôncavo da Bahia. Rev Acad GUETO [periódico na Internet]. 2018 Jun. [acessado 2019 Mar 05]; 5(12):170-186. Disponível em: https://www2.ufrb.edu.br/revistaacademicagueto/images/capa_gueto_12edicao-merged.pdf

20. Lima MRA, Nunes MLA, Klüppel BLP, Medeiros SM, Sá LD. Atuação de enfermeiros sobre práticas de cuidados afrodescentes e indígenas. Rev Bras Enferm [periódico na Internet]. 2016 Set. [acessado $2019 \mathrm{Mar}$ 05]; 69(5):840-846. Disponível em: http://dx.doi. org/10.1590/0034-7167.2016690504

21. Milhomem MSFS. Os desafios para a permanência no ensino superior de estudantes indígenas na Universidade Federal do Tocantins. Rev Relicário [periódico na Internet]. 2017 Jul. [acessado 2019 Mar 05]; 4(8):131144. Disponível em: https://revistarelicario.compresite.net.br/index.php/relicario/article/view/11 
22. Sousa EA, Gois DM. Estudiantes Indígenas en la Universidad Federal del Oeste de Pará (UFOPA), Santarém (Brasil):Waiwai, Arapium y Tupinambá. Boletín Americanista [periódico na Internet]. 2017 Jul. [acessado 2019 Mar 05]; 2(75):113-131. Disponível em: http://revistes.ub.edu/index.php/BoletinAmericanista/article/view/20237

23. Freire P. Educação e Mudança. Rio de Janeiro: Paz e Terra; 1979.

24. Freire P. Pedagogia da autonomia: saberes necessários à prática docente. São Paulo: Paz e Terra; 1996.

25. Menerz CB. Ensino de história, diálogo, intercultural e relações étnico-raciais. Educ real [periódico na Internet]. 2017 Jan. [acessado 2019 Mar 05]; 42(1):5977. Disponível em: http://dx.doi.org/10.1590/2175623661184

26. Fontana RT. O processo de educação em saúde para além do hegemônico na prática docente. Rev contexto educ [periódico na Internet]. 2018 Set. [acessado 2019 Mar 05]; 33(106):84-98. Disponível em: https://doi. org/10.21527/2179-1309.2018.106.84-98

Artigo apresentado em 20/04/2019

Aprovado em 20/08/2019

Versão final apresentada em 03/10/2019 